\title{
Machine Learning for Price Prediction for Agricultural Products
}

\author{
SUSSY BAYONA-ORÉ ${ }^{1,2}$ \\ ${ }^{1}$ Dirección de Investigación, Universidad Autónoma del Perú, Panamericana Sur Km. 16.3, Villa EL \\ Salvador, LIMA-PERÚ \\ RINO CERNA ${ }^{2}$, EDUARDO TIRADO HINOJOZA ${ }^{2}$ \\ ${ }^{2}$ Universidad Nacional Mayor de San Marcos, Ciudad Universitaria - Av. Germán Amézaga, LIMA- \\ PERÚ
}

\begin{abstract}
Family farms play a role in economic development. Limited in terms of land, water and capital resources, family farming is essentially characterized by its use of family labour. Family farms must choose which agricultural products to produce; however, they do not have the necessary tools for optimizing their decisions. Knowing which products will have the best prices at harvest is important to farmers. At this point, machine learning technology has been used to solve classification and prediction problems, such as price prediction. This work aims to review the literature in this area related to price prediction for agricultural products and seeks to identify the research paradigms employed, the type of research used, the most commonly used algorithms and techniques for evaluation, and the agricultural products used in these predictions. The results show that the mostly commonly used research paradigm is positivism, the research is quantitative and longitudinal in nature and neural networks are the most commonly used algorithms.
\end{abstract}

Key-Words: - Machine learning, Price prediction, Agriculture, Farming, Family farm

Received: November 23, 2020. Revised: May 1, 2021. Accepted: May 20, 2021. Published: June 7, 2021.

\section{Introduction}

In spite of the pandemic that we are experiencing, the agricultural sector grew by $1.2 \%$ in January 2021 compared to the same month in 2020, and small producers have been crucial in the sector's recovery.

In 2020, an overall growth increase of $1.3 \%$ was achieved compared to 2019, and this progress was based on an increase in production in the agricultural sector of nearly $3.1 \%$ [1].

Family farms represent $97 \%$ of the agricultural units. More than $83 \%$ of agricultural workers work on family farms. Family labour is a characteristic of family farms with limited capital resources

The prices of agricultural products are closely related to family income, so price stability is important [2]. Further, family farms play an important role in economic development [3]. When farmers decide to plant an agricultural product, they make the decision based upon their previous experiences.
Despite their contributions, family farmers do not have access to the tools large producers use; therefore, they are unable to compete on equal terms.

Choosing the agricultural products to grow is a challenge task for these farmers, as they lack the tools needed to determine which agricultural products will have the best prices when they are ready to go to market.

At this point, machine learning algorithms have been applied in many different sectors to solve prediction problems, but a limited number of studies have been done on price prediction for agricultural products [4], particularly vegetables.

The agricultural sector lacks technological advancements [5] and the computer science field can provide tools, such as big data and machine learning, to improve this situation. The application of machine learning in the agricultural field has largely been focused on the weather, quantity of fertilizer and rainfall prediction [5].

Very little epistemological work in the area of machine learning has been conducted. This work will become more pressing once more techniques 
and technologies for data analysis become available [6]. Due the importance and use of machine learning, is possible that in the near future, philosophers of science will become interested in this topic [7].

The purpose of this work is to explore the research that has been carried out on predicting the prices of agricultural products using machine learning algorithms. The aim here is to understand the evolution in the use of these algorithms, identify the most frequently used algorithms in price prediction for agriculture products and discover the research paradigms and performance metrics used.

This work has been organized as follows. Section 2 describe the theorical framework, while Section 3 presents the Methodology. Section 4 present the results, and Section 5 discusses the findings. Finally, conclusions are presented in Section 6.

\section{Theorical Framework}

\subsection{Machine Learning}

Machine learning, a subdomain of Artificial Intelligence [8], is the study of the use of computer algorithms in formulating accurate predictions [9]. Machine learning involves a learning process and uses training data or experience to progressively improve its performance on a specific task or to make accurate predictions [10].

The data used in machine learning consists of a set of examples and the individual example is described by a set of attributes. These attributes are also known as characteristics or variables [11].

Machine learning can be broadly divided into supervised, unsupervised and reinforcement learning [8]. In supervised learning, "the learner uses a series of labelled samples as training data and predicts all unseen instances" [9].

In unsupervised learning, the learner receives unlabelled training data only and predicts all unseen instances [9]. Unsupervised learning is used primarily for dimensionality reductions and exploratory data analysis [12].

Machine learning has been widely applied and gained in popularity due to its promising results in the domains of classification and prediction [13]. The best-known learning models are the Regression, Clustering, Bayesian, Decision Tree and Artificial Neural Network models [11].

\subsection{Epistemology and the Positivist Paradigm} Epistemology is a branch of philosophy focused on knowledge [14]. Epistemology ask the following question: How do we know something?
Epistemology is useful in that, among other things, it proposes clear solutions to real philosophical problems that address the reality of scientific research.

It deals with ethical problems and moral norms, among other issues [15]. The main problems in the philosophy of technology are the establishment of the peculiar features of a given technical object as opposed to a natural one and distinguishing between technological knowledge and scientific knowledge [15].

As far as research is concerned, technological research does not differ from scientific research: both define the problem, propose solutions and experiment, then test the solutions and make the necessary corrections.

The relationship between machine learning and scientific research has given rise to important epistemological questions [16]. However, given the many advances in machine learning, these advances will be a major topic for the philosophy of science the wrestle with in the near future [7].

The studies related to use of machine learning in prices prediction are performed under an epistemological paradigm. Kuhn [17] states that a paradigm is a set of assumptions that are interrelated with respect to their interpretation of the world.

Paradigms guide professionals within their disciplines since they indicate the problems that must be dealt with [18]. They are closely related to science [19] and some paradigms are positivism, pragmatism, post-positivism and interpretivism.

Positivism affirms "the autonomous, independent, and objective existence of truth" [20]. Knowledge is true if it was created using the scientific method [21]. The positivist paradigm includes quantitative, empirical-analytical, rationalist, systematic management and technological science [22].

\subsection{Performance Metrics}

Among the performance metrics used for the evaluation of prediction problems are the Mean Absolute Error (MAE), Mean Absolute Percentage Error (MAPE), Mean Square Error (MSE) among others.

The MAE is a standard measure of forecast error in time series analysis. and is one of the many metrics for summarizing and evaluating the performances of machine learning models [23].

The RMSE is the square root of the mean square error, meaning that it is the root of the average of squared differences between predictions and observations [23]. 
The MAPE is the size of the error in terms of percentages, so it does not depend on the scale used in a problem. It is the average of the percentage errors without taking their signs into account.

\section{Methodology}

A narrative literature review related to price prediction using machine learning was conducted. Such a literature review often does not specify the methodological process involved in selecting and evaluating papers [24].

The purpose of the review was to determine the research paradigms, performance metrics, and machine learning techniques most used in studies concerning price prediction for agriculture products.

The keywords "machine learning" and "agricultural price prediction" were used in order to create the search string. The snowball method was applied in order to find other papers related to same topic.

The inclusion criteria were: (1) papers focused on price predictions using machine learning, (2) access to full-text articles and (3) papers published in the period 2011-2020 (3). The exclusion criteria was the lack of a statistical and econometric model within a paper.

The relevant information for each selected study was recorded in an electronic database and included information such as title, author, publication year, research paradigm, research design, machine Learning technique, performance metric, country and agricultural product.

\section{Results}

\subsection{Research Paradigms}

The selected studies made no explicit reference to epistemological aspects. Positivism is the paradigm that guided the authors of these studies. These studies focused on specific time ranges and objective facts, while collecting data longitudinally and using them in a recurrent manner. Daily, weekly, monthly and quarterly prices were used in the studies.

Positivism sees dualism and objectivism in the relationship between the knower and what can be known, meaning that the researcher and the object of study are totally independent.

In the cases evaluated, prices were influenced by agricultural productivity, which is very vulnerable and depends to a great extent on the different climatic conditions from one season to another and from one year to another [25]. Kyriazi [25] used quarterly observations spanning the period from 2000 to 2017.

Chen et al. [26] specified that due to the natural climate, the relationship between supply and demand, emergencies and other factors conditions the prices of vegetables.

Zhanga et al. [27] took into consideration the fact that the market prices of agricultural products are affected by factors such as climate, demand and supply and markets and that these prices can change rapidly and are hard to collect. Wu et al. [28] referred to agricultural products as primary goods or raw materials whose prices are irreversibly influenced by exogenous variables.

Some researches, such as Jha et al. [29], used monthly time series, while others used weekly time series [30] and daily time series [31]. That is, there was no pre-established rule as to time period; rather, the period used depended on specific research considerations or data availability.

Table 1 show that all of the studies predicting prices of agricultural products used the positivism paradigm. Further, all of the research was quantitative (Q) and longitudinal (L).

\subsection{Machine Learning Techniques}

The literature review shows that predicting the price of agricultural products using machine learning has been a topic of interest in recent years.

In the studies, the authors compared results by measuring efficiency and/or precision or by utilizing some specific measure developed for the model used (see Table 1).

Table 1. Price Prediction Using Machine Learning Algorithms

\begin{tabular}{llll}
\hline Author & Algorithms & Type & Paradigm \\
\hline Luo et al. [31] & BPNN, GA, RBFN, ANN-GA Integrated model & Q, L & Positivism \\
\hline Wei et al. [32] & BP, Improved BP & Q, L & Positivism \\
\hline Zong et al. [33] & RBFNN, BPNN & Q, L & Positivism \\
\hline Jha et al. [29] & ARIMA, TDNN & Q, L & Positivism \\
\hline Zhanga et al. [27] & WNN & Q, L & Positivism \\
\hline
\end{tabular}




\begin{tabular}{llll}
\hline Xiong et al. [34] & VECM, SSVR, MSVR, VECM-MSVR, ARIMA-MSVR, & Q, L & Positivism \\
& ARIMA-ANN & & \\
\hline Wang et al. [38] & RBF Neural Network & Q, L & Positivism \\
\hline Pinheiro et al. [30] & ANN, ANN-MSSA & Q, L & Positivism \\
\hline Shakoor et al. [37] & $\begin{array}{l}\text { Decision Tree Learning- ID3 (Iterative Dichotomiser 3), } \\
\text { K-Nearest Neighbours Regression }\end{array}$ & Q, L & Positivism \\
\hline Yashavanth et al. [39] & ARIMA, VAR & Q, L & Positivism \\
\hline Wu et al. [28] & AR Model, ARIMA, Time Model, Warning model & Q, L & Positivism \\
\hline Xiong et al. [4] & SARIMA, SARIMA-KF, SVR, TDNN, ELM, STL-ELM & Q, L & Positivism \\
\hline Yu et al. [35] & CRT, Linear Regression, CHAID, SVM, KNN, & Q, L & Positivism \\
\hline Zhang et al. [40] & Exhaustive, BPNN & & \\
\hline Chen et al. [26] & QR-RBF / GDGA. GA SVM, LSTM, WA-LSTM & Q, L & Positivism \\
\hline Dharavath et al. [41] & ARIMA, SARIMA & Q, L & Positivism \\
\hline Drachal [42] & DMA, DMS, MED, ARIMA, Naive & Q, L & Positivism \\
\hline Kyriazi et al. [25] & MZ-regression & Q, L & Positivism \\
\hline Madaan et al. [36] & ARIMA, SARIMA, LSTM & Q, L & Positivism \\
\hline Sabu et al. [3] & SARIMA, Holt-Winter SM, LSTM & Q, L & Positivism \\
\hline Zhang et al. [2] & ANN, SVR, ELM, SMA, MSN-RF, MSN-SVM & Q, L & Positivism \\
\hline Q: Quantitative, L: Longitudinal & & Q, L & Positivism \\
\hline
\end{tabular}

The results show that many algorithms have been used in these studies. The Neural Network models are the most used models at 24 algorithms.

They are followed by the statistical models, with 20 evaluated algorithms. In third place, we have Support Vector Machines, which was used nine times.
The Bayesian and Decision Tree model were used a combined four times. Figure 1 shows the prediction models by year.

The Neural Network models are the most used in the studies identified, and these models are present in all years. In the first two years, eight studies were identified, whereas seven studies were identified and in the last 4 years. 


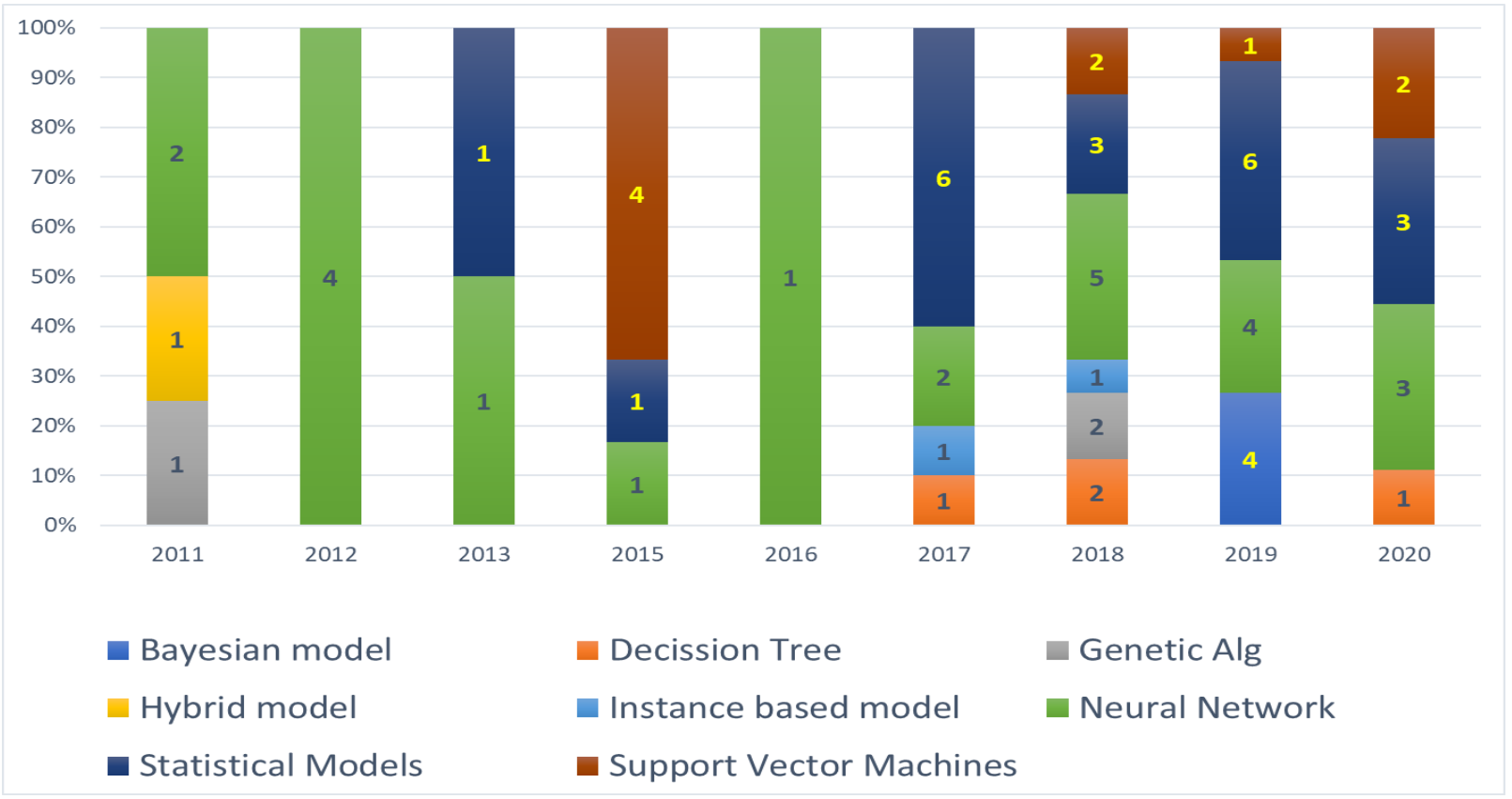

Fig. 1. Use of the different prediction models from 2011 to 2020

The prediction models with the second-highest incidence were the statistical models. Note also that Support Vector Machines first showed up in 2015, then did not show up again in the next 4 years.
Decision Trees, Bayesian models and genetic algorithms have been used.

The predictive models that work best are the Neural Networks, since they have produced better results in nine studies, the most of any method.

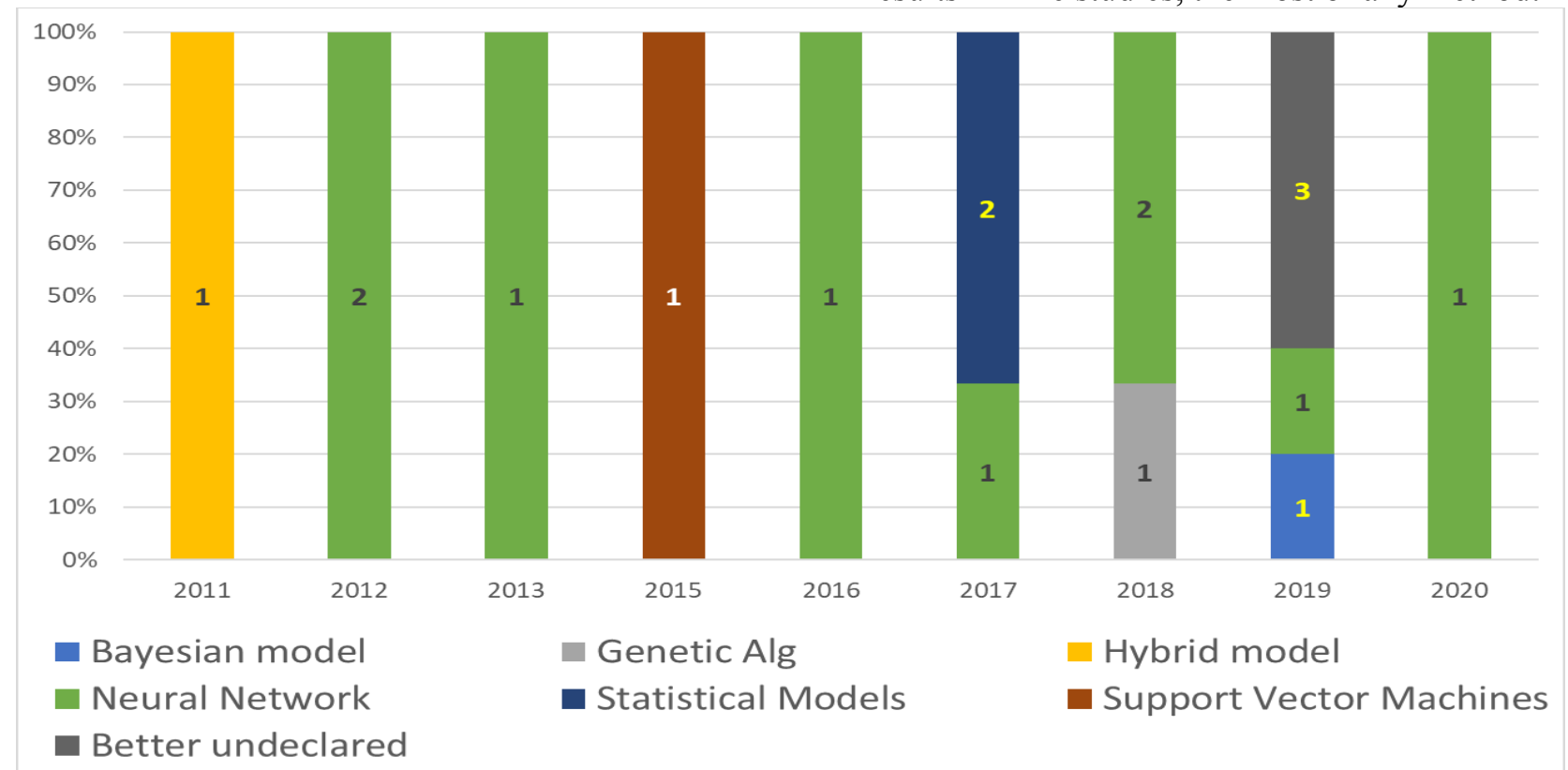

Fig. 2. Prediction models from 2011 to 2020

Finally, the results show a progressive evolution towards the use of Neural Networks, which is mainly due to the results of the experiments.

\subsection{Performance Metrics}

To evaluate performances, the authors of the studies used different measures. Table 2 shows the main performance metrics used in these studies. 
Table 2. Performance metrics used in the studies

\begin{tabular}{|l|l|}
\hline Metric & Studies \\
\hline RMSE & $[3] 25][29][36][39][42][3]$ \\
\hline MAPE & {$[33][34][35][39][40]$} \\
\hline MAE & {$[26][31][42]$} \\
\hline Varied & {$[2][28][37][38]$} \\
\hline MSE & {$[26][30]$} \\
\hline MAD & {$[29][25]$} \\
\hline MASE & {$[4][42]$} \\
\hline R2 & {$[27]$} \\
\hline SMAPE & {$[4]$} \\
\hline SPA & {$[4]$} \\
\hline MIV & {$[34]$} \\
\hline
\end{tabular}

It is evident that some measurement techniques are used more frequently, namely, the RMSE, MAPE and MAE.
Table 3 shows the different agricultural products evaluated in price prediction research. Some researchers have examined only one agricultural product, for example, Chen et al. [26] studied cabbage using price data from march (2010) to may (2019), Wang et al. [38] and Zhan et al. [40] investigated soybeans, Yashavanth et al. [39] studied coffee using monthly prices from January 2001 to May 2013 and, finally, Zhanga et al. [27] studied tomato.

Madaan et al. [36], Sabu et al. [3] Xiong et al. [34] studied two agricultural products. The remaining researchers used several products to validate their prediction models.

According to the studies identified, China was the subject of the most research, with 11 studies located there. It also had the largest number of agricultural products evaluated (17).

\subsection{Agricultural Product Price Prediction}

Table 3. Agricultural products evaluated in price prediction research

\begin{tabular}{|l|l|l|}
\hline Author & Products & Location \\
\hline Chen et al. [26] & Cabbage & China \\
\hline Dharavath et al. [41] & Mango, Pineapple, Vegetables & India \\
\hline Drachal [42] & Wheat, Corn, Soybean & EUA \\
\hline Jha et al. [29] & Soybean, Mustard Seed & India \\
\hline Kyriazi et al. [25] & Vegetables, Tomato, Potato & Europe \\
\hline Luo et al. [31] & Vegetables & China \\
\hline Madaan et al. [36] & Onion, Potato & India \\
\hline Pinheiro et al. [30] & Sugar, Cotton, Corn, Coffee, Soybean & Brazil \\
\hline Sabu et al. [3] & Areca Nut & India \\
\hline Shakoor et al. [37] & Rice, Potato, Wheat, Others & India \\
\hline Wang et al. [38] & Soybean & China \\
\hline Wei et al. [32] 3 [] & Retail Food Price Index & China \\
\hline Wu et al. [2] & Bean, Watermelon, Rice, Banana, Others & China \\
\hline Xiong et al. [34] & Cotton, Corn & China \\
\hline Xiong et al. [4] & Vegetables & China \\
\hline Yashavanth et al. [39] & Coffee & India \\
\hline Yu et al. [35] & Not listed & China \\
\hline Zhang et al. [40] & Soybean & China \\
\hline Zhang et al. [2] & Wheat Bran, Corn, Others & China \\
\hline Zhanga et al. [27] & Tomato & China \\
\hline Zong et al. [33] & Rice, Sugar & China \\
\hline
\end{tabular}


In number of studies, it is followed by India with 6 studies (12 agricultural products evaluated). Far behind are Brazil, the European countries and a global view.

The main agricultural products evaluated in price prediction research were soybean, vegetables, corn, potato, rice, coffee, tomato, sugar, cotton and wheat.

\section{Discussion}

The machine learning models used for price prediction vary between regions and agricultural products but also vary due to the availability and diversity of the data. Thus, establishing the real value of any model is nearly impossible.

Even though Neural Networks showed a higher level of success during the evaluation period, it cannot be concluded that it is the best prediction model in all cases. Further, there is no single technique or tool best equipped to evaluate the performances of the different machine learning models nor can there be comprehensive comparisons of these models. There is a tendency on the part of researchers to use Neural Networks or this type of algorithm in combination with other algorithms (hybrid model).

The agricultural products evaluated in price prediction research were selected by the availability of the necessary data across time. Thus, it was impossible to compare results directly. Only a few countries were considered in research related to price prediction. China and India were subject to the largest amount of research, so the products examined were closely related to their domestic markets.

Establishing the particular conditions governing the price of each agricultural product can provide new information on common aspects to be considered when attempting to improve the performance or reliability of the prediction or prediction model proposed. Also, the major challenge is to have complete and accurate data on time. Ibrahim et al. [43] agree that a network or un portal which facilitate collecting data is relevant in this type of studies.

\section{Conclusions}

Family farms play a role in economic development and are characterized by the use of family labour. Deciding which product to plant to obtain the best price at harvest is a challenge. In order to learn what tools have been used to predict prices for agricultural products, a literature review was carried out. The literature review results show that it is necessary to address the epistemological aspect of research involving machine learning to improve the understanding and reliability of the results. Most of the studies identified used the positivist paradigm. The research approach that the authors used was quantitative and longitudinal. Also, several machine learning models were used to predict the price of agricultural products. The researchers showed a preference for Neural Network-based algorithms due to the results obtained by this type of algorithm in terms of accuracy and precision in price prediction compared to other types of algorithms. The results of this study can be used by research community, farmers and specialists interested in price prediction of agricultural products.

\section{References}

[1] Andina

https://andina.pe/agencia/noticia-sectoragropecuario-empieza-alza-2021-y-crece-12enero836161.aspx\#: :text=El\%20sector\%20agropec uario $\% 20$ inici $\% \mathrm{C3} \% \mathrm{~B} 3 \% 20 \mathrm{el}$,Agrario $\% 20 \mathrm{y} \%$ 20Riego\%20(Midagri).

[2] Zhang, D., Chen, S., Liwen, L., Xia, Q. (2020). Forecasting agricultural commodity prices using model selection framework with time series features and forecast horizons. IEEE Access, Vol. 8, pp. 28197-28209.

[3] Sabu, K. M., Kumar, T. K. M. (2020). Predictive analytics in Agriculture: Forecasting prices of Arecanuts in Kerala. Procedia Computer Science, Vol. 171, pp. 699-708.

[4] Xiong, T., Li, C., Bao, Y. (2018). Seasonal forecasting of agricultural commodity price using a hybrid STL and ELM method: Evidence from the vegetable market in China. Neurocomputing, Vol. 275, pp. 2831-2844.

[5] Rakhra, M., Soniya, P., Tanwar, D., Singh, P., Bordoloi, D., Agarwal, P., Verma, N. (2021). Crop price prediction Using random forest and decision tree regression: A review. Materials Today: Proceedings, In Press.

[6] Floridi, L. (2012) Big data and their epistemological challenge. Philos. Technol., Vol. 25, pp. 435-437.

[7] Boge, F. J., Poznic, M. (2020). Machine learning and the future of scientific explanation. Journal for General Philosophy of Science, 1-6.

[8] Saha, D., Annamalai, M. (2021). Machine learning techniques for analysis of hyperspectral images to determine quality of 
food products: A review. Current Research in Food Science, Vol. 4, pp. 28-44.

[9] Subasi, A. (2020). Machine learning techniques. Practical machine learning for data analysis using Python, Academic Press.

[10] Mohri (2018). Foundations of machine learning, MIT Press.

[11] Liakos, K., Busato, P., Moshou, D., Pearson, S., Bochtis, D. (2018). Machine learning in agriculture: A review. Sensors, Vol. 18, No. 2674, pp. 1-26.

[12] Jordan, M., Mitchell, T. (2015). Machine learning: Trends, perspectives, and prospects. Science, Vol. 349, No. 6245, pp. 255-260.

[13] Bunker, R., Thabtah, F. (2019) A machine learning framework for sport result prediction. Applied Computing and Informatics, Vol. 15, No. 1, pp. 27-33.

[14] Couper, P. (2020). Epistemology. International Encyclopedia of Human Geography, pp. 275284. doi:10.1016/b978-0-08-102295-5.106407.

[15] Bunge, M. (2002). Epistemología: curso de actualización. Siglo XXI, México.

[16] Resch, M., Kaminski, A. (2019). The epistemic importance of technology in computer simulation and machine learning. Minds and Machines, Vol. 29. No. 1, pp. 9-17.

[17] Kuhn, T. (1962). The structure of scientific revolutions, University of Chicago Press.

[18] Ramos, C. A. (2015). Los paradigmas de la investigación científica. Avances En Psicología, Vol. 23, No. 1, pp. 9-17.

[19] Kankam, P. (2019). The use of paradigms in information research. Library \& Information Science Research, Vol. 41, No. 2, pp. 85-92.

[20] Aliyu, A., Bello, M., Kasim, R., Martin, D. (2014). Positivist and non-positivist paradigms in social science research: Conflicting paradigms or perfect partners? Journal of Management and Sustainability, Vol. 4, No.3, pp. 79-95.

[21] McGregor, S., Murnane, J. (2010). Paradigm, methodology and method: Intellectual integrity in consumer scholarship. International Journal of Consumer Studies, Vol. 34, No. 4, pp. 419427.

[22] Ricoy, C. (2006). Contribución sobre los paradigmas de investigación. Revista do Centro de Educação, Vol. 31, No. 1, pp. 11-22.

[23] Venishetty, S. V. (2019). Machine Learning Approach for Forecasting the Sales of Truck Components, Faculty of Computing, Blekinge Institute of Technology.
[24] Barczak, G. (2017). From the editor: Writing a review article. The Journal of Product Innovation Management, Vol. 34, No. 2, pp. 120-121.

[25] Kyriazi, F., Thomakos, D., Guerard, J. (2019). Adaptive learning forecasting, with applications in forecasting agricultural prices. International Journal of Forecasting, Vol. 35, No. 4, pp.1356-1369.

[26] Chen, Q., Lin, X., Zhong, Y. \& Xie, Z. (2019) Price prediction of agricultural products based on wavelet analysis-lstm. In Proceedings - 2019 IEEE Intl Conf on Parallel and Distributed Processing with Applications, Big Data and Cloud Computing, Sustainable Computing and Communications, Social Computing and Networking, ISPA/BDCloud/SustainCom/SocialCom 2019. Institute of Electrical and Electronics Engineers, Inc.

[27] Zhanga, J. H., Kongb, F. T., Wu, J. Z., Zhu, M. S., Xu, K., Liu, J. J. (2014). Tomato price time series prediction model based on wavelet neural network. Applied Mechanics and Materials, Vol. 644, pp. 2636-2640.

[28] Wu, H., Wu, H., Zhu, M., Chen, W., Chen, W. (2017). A new method of large-scale short-term forecasting of agricultural commodity prices: Illustrated by the case of agricultural markets in Beijing. Journal of Big Data, Vol. 4 No. 1, pp. $1-22$.

[29] Jha, G., Sinha, K. (2013). Agricultural price forecasting using neural network model: An innovative information delivery system. Agricultural Economics Research Review, Vol. 26, No. 2, pp. 229-239.

[30] Pinheiro, C., de Senna, V. (2017). Aplicação de análise multivariada e redes neurais para previsão de preços no mercado agrícola brasileiro. Ciencia Rural, Vol. 47, No. 1. pp. 17.

[31] Luo, C., Wei, Q., Zhou, L., Zhang, J., \& Sun, S. (2011). Prediction of vegetable price based on neural network and genetic algorithm. IFIP Advances in Information and Communication Technology Vol. 346, pp. 672-681.

[32] Wei, M., Zhou, Q., Yang, Z., Zheng, J. (2012). Prediction model of agricultural product's price based on the improved BP neural network. In ICCSE 2012 - Proceedings of 2012 7th International Conference on Computer Science and Education (pp. 613-617). https://doi.org/10.1109/ICCSE.2012.6295150

[33] Zong, J., Zhu, Q. (2012). Price forecasting for agricultural products based on $\mathrm{BP}$ and $\mathrm{RBF}$ 
Neural Network. In ICSESS 2012 Proceedings of 2012 IEEE 3rd International Conference on Software Engineering and Service Science (pp. 607-610). https://doi.org/10.1109/ICSESS.2012.6269540.

[34] Xiong, T., Li, C., Bao, Y., Hu, Z., Zhang, L. (2015). A combination method for interval forecasting of agricultural commodity futures prices. Knowledge-Based Systems, Vol. 77, pp. 92-102.

[35] Yu, Y., Zhou, H., Fu, J. (2018). Research on agricultural product price forecasting model based on improved BP neural network. Journal of Ambient Intelligence and Humanized Computing, https://doi.org/10.1007/s12652018-1008-8.

[36] Madaan, L., Sharma, A., Khandelwal, P., Goel, S., Singla, P., Seth, A. (2019). Price forecasting \& anomaly detection for agricultural commodities in India. In COMPASS 2019 Proceedings of the 2019 Conference on Computing and Sustainable Societies (pp. 5264). Association for Computing Machinery, Inc.

[37] Shakoor, M. T., Rahman, K., Rayta, S. N., \& Chakrabarty, A. (2017). Agricultural production output prediction using Supervised Machine Learning techniques. In 2017 1st International Conference on Next Generation Computing Applications, NextComp 2017 (pp. 182-187). Institute of Electrical and Electronics Engineers Inc. https://doi.org/10.1109/NEXTCOMP.2017.801 6196.
[38] Wang, Y., Su, X., Guo, S. (2016). The optimal confidence intervals for agricultural products' price forecasts based on hierarchical historical errors. Entropy, Vol 18, No. 12, pp. 1-17.

[39] Yashavanth, B., Singh, K., Paul, A., Paul, R. (2017). Forecasting prices of coffee seeds using vector autoregressive time series model. Indian Journal of Agricultural Sciences, Vol. 87, No. 6, pp. 754-758.

[40] Zhang, D., Zang, G., Li, J., Ma, K., Liu, H. (2018). Prediction of soybean price in China using QR-RBF neural network model. Computers and Electronics in Agriculture, Vol. 154, pp. 10-17.

[41] Dharavath, R., Khosla, E. (2019). Seasonal ARIMA to forecast fruit and vegetable agricultural prices. In Proceedings - 2019 IEEE International Symposium on Smart Electronic Systems, iSES 2019 (pp. 47-52). Institute of Electrical and Electronics Engineers, Inc. https://doi.org/10.1109/iSES47678.2019.00023

[42] Drachal, K. (2019). Analysis of agricultural commodities prices with new Bayesian model combination schemes. Sustainability, Vol. 11, pp. 1-23.

[43] Ibrahim, R. E., Elramly, A., Hassan, H. M. Open Systems Science: Digital Transformation and Developing Business Model toward Smart Farms' Platform. International Journal of Circuits, Systems and Signal Processing, Vol. 14, pp. 1054-1073.

\section{Creative Commons Attribution License 4.0 (Attribution 4.0 International, CC BY 4.0)}

This article is published under the terms of the Creative Commons Attribution License 4.0

https://creativecommons.org/licenses/by/4.0/deed.en_US 